\title{
Long-Term Protective Factor Outcomes of Evidence-Based Interventions Implemented by Community Teams through a Community-University Partnership
}

\author{
Cleve Redmond, \\ Partnerships in Prevention Science Institute, lowa State University \\ Richard L. Spoth, \\ Partnerships in Prevention Science Institute, lowa State University \\ Chungyeol Shin, \\ Partnerships in Prevention Science Institute, lowa State University \\ Lisa M. Schainker, \\ Partnerships in Prevention Science Institute, lowa State University \\ Mark T. Greenberg, and \\ Prevention Research Center, The Pennsylvania State University \\ Mark Feinberg \\ Prevention Research Center, The Pennsylvania State University
}

\section{Abstract}

It is becoming increasingly common for community teams or coalitions to implement programming for children and families designed to promote positive youth development and prevent adolescent problem behaviors. However, there has been only limited rigorous study of the effectiveness of community teams' programming efforts to produce positive outcomes. This study employed a community-level randomized control design to examine protective parent and youth skills outcomes of evidence-based preventive interventions selected from a menu and delivered by community teams supported by a community-university partnership model called PROSPER. Twenty-eight rural communities in two states were randomized across intervention and control conditions. Data were collected through written questionnaires that were completed by approximately 12,000 middle school students in the fall of the $6^{\text {th }}$ grade, prior to intervention delivery, and again in the spring of the $7^{\text {th }}, 8^{\text {th }}$, and $9^{\text {th }}$ grades. Positive intervention effects were found for youth, parent, and family outcomes (e.g., association with antisocial peers, child management, parent-child affective quality) at each post-intervention assessment point. Improvements in these family and youth skill outcomes are expected to support long-term reductions of adolescent problem behaviors, such as substance abuse.

Epidemiological data indicates that the prevalence of youth problem behaviors, including substance use, violence, and academic failure, remains high (Biglan et al., 2004; Johnston et al., 2006; Romer, 2003; Spanier, 1998). Moreover, such problems are not limited to urban areas; studies have shown increasing levels of substance use in rural areas, with use rates for many substances at or exceeding those in urban areas (National Center on Addiction and Substance Use [CASA], 2000; Johnston et al., 2008; Spoth et al., 2007). These studies

Correspondence should be addressed to Cleve Redmond, Associate Director, Partnerships in Prevention Science Institute, ISU Research Park, Building 2, Suite 500, 2625 North Loop Drive, Iowa State University, Ames, Iowa 50010, U.S.A.; 515-294-0114; cleve@iastate.edu. 
underscore the critical need for the diffusion of effective interventions designed to reduce the risk for such behaviors in both urban and traditionally underserved rural areas. An increasingly popular approach to addressing this need is through the delivery of evidencebased prevention programming implemented by community-based partnerships, in the form of coalitions or teams (Butterfoss et al., 1996; Kumpfer et al., 1993; Minkler, \& Wallerstein, 2002). However, to date there has been little empirical research evaluating the effectiveness of this approach and it has been argued that the lack of rigorous effectiveness studies has hindered the assessment of their practical public health benefit (Glasgow et al., 2004). Such effectiveness studies examine intervention outcomes when interventions are implemented under "real world" delivery conditions, in contrast to more highly controlled intervention efficacy studies designed to assure strong internal validity (Flay et al., 2005).

Highlighting the need for further study of community-based programming outcomes are concerns about program implementation quality in situations where community teams receive little or no technical assistance to support program delivery (Mihalic \& Irwin, 2003). For example, recruitment rates for community-managed interventions targeting general population families are generally low (Spoth, Clair, et al., 2007) and the fidelity of intervention delivery may be subject to substantial deterioration (Dzewaltowski et al., 2004). In addition, even when high quality implementation is initially supported through a research grant, the delivery of such interventions is often not sustained following the removal of research funding for implementation (Mihalic \& Irwin, 2003). The following section describes a community-university partnership model called PROSPER (PROmoting Schoolcommunity-university Partnerships to Enhance Resilience), that was designed to facilitate community-teams' sustained, high quality delivery of school-based and family-focused evidence-based interventions (Spoth et al., 2004). Moreover, by utilizing two existing infrastructures for the delivery of evidence-based interventions, the public school system and University Extension (the outreach arm of land-grant universities), the PROSPER model is well suited to support intervention delivery in rural communities that might otherwise lack the capacity to support such sustained, high quality delivery.

\section{Partnership Model for the Delivery of Preventive Interventions}

The PROSPER model has a three-tier structure, consisting of (1) community teams, (2) state-level university researchers, and (3) a prevention coordinating team linking the community teams with university researchers. University Extension plays a central role in model implementation. Local Extension staff serve as community team leaders, and regional or state-level Extension staff serve as the Prevention Coordinators (PCs) that comprise the prevention coordinating team that provides direct technical assistance to community teams. Serving on the community teams with the Extension-based team leaders are public school representatives (serving as team co-leaders), community human service agency representatives, and other community stakeholders (e.g., youth and parents).

Because of the large number of risk and protective factors related to adolescent problem behaviors that originate in the home and school environments (Dishion et al., 1991; Hawkins et al., 1992; Romer, 2003), the PROSPER model was designed to support community-team managed multicomponent intervention delivery that includes both a school-based and a family-focused intervention targeting general population middle school students. All interventions supported through PROSPER have been previously evaluated and are considered evidence-based (e.g., listed as model programs by the Substance Abuse and Mental Health Administration).

The PROSPER model represents a hybrid of two models, one in which intervention implementation is entirely conducted by a community team or coalition without direct or 
indirect involvement by prevention scientists, and one in which implementation is closely controlled by paid staff directly supervised by a research team. In the hybrid model, community teams have primary responsibility for implementation; however, they receive ongoing technical assistance and support from the PCs who, in turn, receive support from, and have oversight by, the university research team.

Community teams, comprising the first tier of the PROSPER partnership model, are typically comprised of 10 to 15 members and are responsible for prevention program selection and implementation, as well as the long-term sustainability of intervention delivery. Key program implementation responsibilities include family-focused program meeting logistics, hiring of program facilitators, and the recruitment of families. Key sustainability tasks include fund-raising and grant writing to support program delivery. Community teams are led by local Extension System staff, typically specializing youth or family programming with experience in community leadership development. Community teams are co-led by a local school district representative who serves as the primary liaison between the community team and the school district, coordinating with the district on a range of issues, including school-based program implementation. Rounding out the community teams are local community service providers and other stakeholders including parents and youth.

Prevention Coordinators comprise the second tier of PROSPER model. The Extension-based PCs function as the most direct technical assistance providers to community teams, attending community team meetings (usually held once per month) and maintaining regular contact with the community team leaders via bi-weekly (or more frequently, as needed) phone calls. PCs provide technical assistance to community teams around a broad range of issues, including those related to program selection and implementation (e.g., information on program research base and delivery format, the development of local recruitment strategies for program participants, the development and maintenance of program delivery fidelity), team processes (e.g., effective meeting facilitation, new member orientation), and sustainability (e.g., the development of local fund raising strategies, effective grant writing). PCs also coordinate facilitator trainings for the family-focused and school-based interventions, as well as monitor and document community team functioning.

University researchers comprise the third PROSPER model tier. This state-level team serves as a second level of technical assistance for the community teams responsible for intervention implementation. The state-level research team meets regularly with PCs to assist with technical assistance issues, addressing unusual community team problems, and to keep PCs informed of relevant research findings. PCs, in coordination with the state-level research team, also conduct regular (three to four times per year) meetings for community team leaders, focusing on timely topics of relevance for community teams, as well as annual statewide meetings for attended by all community team members. The PROSPER model and the various functional roles are described more thoroughly elsewhere (see Spoth et al., 2004).

Examinations of the PROSPER model conducted to date suggest that it is an effective mechanism for supporting the high quality delivery of evidence-based interventions by community teams. Trained observers attending the family-focused and school-based interventions reported uniformly high rates of implementation adherence for both types of programs, with average adherence ratings of over 90\% (Spoth, Guyll, et al., 2007). High rates of recruitment for the family-focused intervention also were demonstrated, averaging $17 \%$ across the 14 intervention communities, in contrast to typical rates for communitybased preventive interventions of from 1\% to 6\% (Spoth, Clair, et al., 2007). In addition, early findings indicate delayed onset and reduced rates of substance use among $7^{\text {th }}$ graders 
in communities with PROSPER-supported intervention delivery (Spoth, Redmond, et al., 2007). The current paper extends the research base on the PROSPER model through an examination of intervention-targeted parent, family and youth skills outcomes 1, 2, and 3 years following intervention. PROSPER-supported intervention effects on these protective factor outcomes are expected to play a significant role in the reduction of subsequent longterm adolescent problem behaviors, such as substance abuse.

\section{Method}

\section{Community Selection and Assignment}

Participants were two cohorts of middle school students from 28 community school districts recruited from Iowa and Pennsylvania. Cohort 1 students were in the 6th grade during the 2002-2003 school year; Cohort 2 students were in the 6th grade during the 2003-2004 school year. Primary project eligibility criteria for communities were: (a) a school district enrollment between 1,300 and 5,200 students and (b) at least 15\% of the student population eligible for free or reduced cost school lunches (to ensure economic diversity). In addition, communities in which over half of the residents were either employed by or attending a college or university were excluded from the study, as were communities that were involved in other university-affiliated prevention research projects with youth. Within each state, communities were blocked (matched) on school district size and geographic location; they were then randomly assigned to either the partnership-based intervention delivery condition or the control condition. During the first year, two communities (one in each state) withdrew from the study and were replaced. The 28 study communities consisted of rural towns and small cities across the two states. Populations, based on the 2000 census, ranged from 6,975 to 44,510 . Community recruitment procedures are comprehensively described elsewhere (Spoth, Clair, et al., 2007).

\section{Participant Characteristics}

Across the two cohorts of middle school students in the 28 project school districts, a total of 11,931 students ( $90 \%$ of those eligible) completed pretest surveys in the fall of their 6thgrade year. Among those pretested, 10,706 (90\%) remained enrolled in their project school and completed the Spring of 7 th-grade assessment. Sample stability in project school districts remained high through the 9th-grade assessment; the Spring of 8th-grade assessment was completed by $10,170(85 \%)$ of those pretested, and the Spring of 9th-grade assessment was completed by 9,438 (79\%) of those pretested. At the time of the baseline assessment, the sample was distributed relatively evenly across the two states (approximately 50\% in both IA and PA) and intervention condition (51\% intervention; $49 \%$ control). The majority of the students were White (85\%); the largest minority category was Hispanic/Latino (5\%), followed by African American (3\%). There were similar numbers of girls $(51 \%)$ and boys $(49 \%)$ in the sample. A little under two-thirds (64\%) of all students reported living with both of their biological parents. Slightly less than one-third $(31 \%)$ reported receiving free or reduced cost school lunches. Cohort 1 students comprised $51 \%$ of the total sample.

\section{Intervention Selection and Delivery}

Community teams were formed in intervention communities to manage preventive intervention delivery supported by the PROSPER model. Control condition communities received no project support for prevention programming, but were free to implement whatever programming their communities and school districts normally provided. Interviews with key stakeholders (i.e., Extension staff, school district representatives, and human service agency representatives) in control communities indicated that virtually all communities engaged in some prevention efforts for youth and families. Although most 
programming offered was not evidence-based, one or more evidence-based interventions of the types supported through PROSPER were offered in six of the 14 control communities; specific information concerning the numbers of families and youth served by those interventions, and the quality of intervention delivery was not available.

Following their formation in intervention communities, community teams began the process of selecting a universal family-focused program from a menu of three evidence-based interventions provided by the university research team. To assist them in their decision, presentations and written materials describing each program and its evidence-base were provided to community teams at Iowa and Pennsylvania statewide workshops.

Subsequently, each community team held a meeting to select their community's program. Each of the 14 community teams chose the Strengthening Families Program: For Parents and Youth 10-14 (SFP:10-14-Molgaard et al., 1997; Molgaard \& Spoth, 2001). PCs attending the program selection meetings reported that the principal factor leading to the selection of the SFP:10-14 was its inclusion of youth in each program session; the other two family-focused programs on the menu either involved parents exclusively (the Adolescent Transitions Program—Dishion et al., 1996), or involved youth in only one program session (Preparing for the Drug Free Years-Haggerty et al., 1999). In addition to program selection, community teams were responsible for the hiring of program facilitators, physical and logistical arrangements for program meetings, and for recruiting families into the program. The program was delivered to Cohort 1 students and their families during the spring semester of the students' 6th-grade school year (2002-2003).

Following delivery of the family-focused program, community teams were provided with information (through written materials and presentations at the second statewide workshop) on a menu of evidence-based classroom programs for middle school students. With input from the middle-school teaching staff, teams selected a school-based intervention from among the three on the program menu. Each of the three school programs was selected by four or more of the 14 intervention communities (see below); school-based programs were implemented as part of the regular 7th-grade school curriculum during the following (20032004) school-year. Also during the 2003-2004 school year, Cohort 2 6th graders and their families were offered the family-focused program; Cohort 2 students received the schoolbased program during the following (2004-2005) school year (when they were in the 7th grade).

\section{Family-Focused Intervention}

The Strengthening Families Program: For Parents and Youth 10-14(SFP:10-14), implemented by each of the 14 intervention communities, is based upon empiricallysupported family risk and protective factor models (DeMarsh \& Kumpfer, 1986; Kumpfer et al., 1996; Molgaard et al., 2000). The long-range goal of the SFP:10-14 is to reduce youth substance use and other problem behaviors. Intermediate goals include the enhancement of parental skills in nurturing, limit-setting, and communication, as well as youth prosocial and peer resistance skills. The SFP:10-14 is implemented in seven two-hour sessions, delivered once each week for seven consecutive weeks. Each session includes separate, concurrent one-hour parent and youth skills-building segments, followed by a one-hour joint family segment. SFP:10-14 program sessions were offered in community facilities after school hours. Each session required three facilitators, one for the parent group segment and two for the youth group segment.

Across the two cohorts, a total of 1,012 families (17\% of those eligible), represented by approximately 2,750 family members, attended the SFP:10-14 in the 14 schools assigned to the intervention condition. Ninety percent of families who attended the first session attended a total of four or more sessions and 63\% attended six or seven sessions. SFP:10-14 group 
sizes ranged from three to 15 families, with an average group size of eight families and an average of 20 individuals per session. Each team of SFP:10-14 facilitators was observed two or three times to assess their adherence to program content and protocols. Fidelity observations showed average coverage of component tasks and activities was $93 \%$ in the family segments, $88 \%$ in the parent segments, and $91 \%$ in the youth segments (Spoth, Guyll, et al., 2007).

\section{School-Based Interventions}

Each of the evidence-based, universal classroom programs offered was selected by a number of communities; Project ALERT and Life Skills Training were each selected by four intervention communities, while All Stars was selected by six. Each of the school-based programs was implemented in regular classroom sessions during the 7th grade for students in Cohorts 1 and 2. Each classroom of students receiving the intervention was observed (generally twice) to assess fidelity to program content and delivery process. Because the school-based programs were incorporated into the schools' regular curriculum, virtually all $7^{\text {th }}$ grade students enrolled in the intervention condition schools received their community's selected school-based program.

Project ALERT is an 11 session program based on the social influence model of prevention and integrates three theories of behavior change: the health belief model, which focuses on cognitive factors that motivate health behavior (Rosenstock et al., 1988); the social learning model, which emphasizes social norms and significant others as key determinants of behavior (Bandura, 1977); and the self-efficacy theory of behavior change, which maintains that the belief that one can accomplish a task is essential to effective action (Bandura, 1986). The objectives of Project ALERT are to: change students' beliefs about substance use norms and about the social, emotional, and physical consequences of using substances; help students identify and resist pro-substance use pressures from parents, peers, the media, and others; and build resistance self-efficacy. Implementer adherence to program manual content was assessed at $89 \%$ across the two cohorts of students.

All Stars is a 13 session character education and problem behavior prevention program designed to reduce adolescent substance use and violence. It is based on social learning theory (Bandura, 1977) and problem behavior theory (Jessor \& Jessor, 1977). The objectives of All Stars are to: influence students' perceptions about substance use and violence; increase the accuracy of students' beliefs about peer norms regarding substance use and violence; have students make a personal commitment to avoid substance use and violent behavior; and increase students' school bonding (Hansen, 1996). Program fidelity was assessed at $90 \%$ across the two cohorts of students.

Life Skills Training (LST; Botvin, 1996, 2000) is a 15 session program, and like All Stars, is based on social learning theory (Bandura, 1977) and problem behavior theory (Jessor \& Jessor, 1977). The primary goals of LST are to promote skill development (e.g., peer resistance, self-management, general social skills) and to provide a knowledge base to support avoidance of substance use. Program fidelity for LST was assessed at $89 \%$ across the two cohorts of students.

\section{Outcome Measures}

The current study includes student-report measures of youth, parent, and family competencies and risk and protective factors targeted by the interventions delivered as part of PROSPER. These outcomes are consistent with prior risk and protective factor research (Dishion et al., 1991; Hawkins et al., 1992; Romer, 2003), highlighting the important influences of parents and peers, as well as with the research bases underpinning each of the 
programs delivered, as described above. Data were collected via machine scannable questionnaires that were administered to students in classrooms by trained university research staff. To ensure confidentiality, two questionnaire forms, each with a different item order, were used and teachers were not permitted to handle or view the completed questionnaires. Participation in this study was voluntary and informed consent/assent procedures for students and their parents were approved by the university institutional review boards in both states.

General Child Management included 13 five-point Likert-type items, with response categories ranging from Always to Never and was comprised of four subscales: (1) Consistent Discipline (four items; average alpha across waves and cohorts $=.76$ ); e.g., "When my parents discipline me, the kind of discipline I get depends on their mood"); (2) Harsh Discipline (one item; e.g., "When I do something wrong, my parents lose their temper and yell at me"); (3) Child Monitoring (four items; average $a=.80$; e.g., "My parents know who I am with when I am away from home"); and (4) Inductive Reasoning (three items; average $a=.84$; "My parents give me reasons for their decisions"). Average alpha reliability for the combined 13-item General Child Management scale in the current study was .76. Items for all scales were coded so that higher scores represented more positive child management strategies.

Parent-Child Affective Quality was based on students' perceptions of both the mother-child and father-child relationships, and assessed affective quality expressed by each member of the dyad (e.g., expressions of warmth by the child toward the father and expressions of warmth by the father toward the child). The three items used to assess affective quality from the child to the father were: "During the past month, when you and your dad have spent time talking or doing things together, how often did you let him know you really care about him?”; “...how often did you act loving and affectionate toward him?"; and “...how often did you let him know that you appreciate him, his ideas, or the things he does?" (average alpha across waves and cohorts was .97). Similar items were used to assess affective quality from the father to the child (average $a=.97$ ), from the child to the mother (average $a=$. 93 ), and from the mother to the child (average $a=.92$ ). Responses were based on a fivepoint Likert-type scale ranging from Always or Almost Always to Never or Almost Never. Average alpha reliability for the combined 12-item Parent-Child Affective Quality scale in the current study was .96. In all instances, items were coded so that higher scores represented higher levels of affective quality.

Parent-Child Activities were assessed with four six-point items addressing typical parentchild activities during the past month (average alpha across waves and cohorts was .88). Response categories ranged from Not during the past month to Everyday. Examples of activity items include: "Work on homework or a school project together," "Work on something together around the house," and "Do something active together, like playing sports, bike riding, exercising, or going for a walk." Higher scores indicate more frequent parent-child activities.

Family Environment was assessed as a composite construct with seven items from the Moos and Moos (1986) Family Environment Scale addressing family cohesion, conflict, and organization. Example items include: "Family members really help and support each other," "Family members rarely become openly angry," and "Activities in our family are pretty carefully planned." The response options were on a five-point Likert-type scale ranging from Strongly Agree to Strongly Disagree; alpha reliability averaged .77 across cohorts and assessment waves. Items were coded so that higher scores represented a more positive family environment. 
Substance Refusal Intentions were assessed with five items concerning the likelihood that youth would refuse an offer of substance use (e.g., "How likely are you to say 'no' when someone tries to get you to drink beer, wine, or liquor?"). Items addressed offers of alcohol, tobacco, inhalants, marijuana, and other illicit drugs. Responses were assessed on a fivepoint Likert scale ranging from Definitely would not say "no" to Definitely would say "no." Alpha reliability averaged .87 across cohorts and assessment waves. Items were coded so that higher scores represented higher likelihoods of substance use refusal.

Substance Refusal Efficacy assessed how confident students were in their ability to refuse a substance use offer from a friend (e.g., "How confident are you that you could do well in refusing marijuana/pot offered by a friend?"). The three items addressed alcohol, tobacco, and marijuana. Responses were assessed on a five-point Likert scale ranging from Not At All Confident to Very Confident. Alpha reliability averaged .91 across cohorts and assessment waves. Items were coded so that higher scores represented higher levels of refusal efficacy.

Substance Use Plans was assessed with seven items concerning the likelihood of substance use during the next year (e.g., "Do you think you will use marijuana or hashish within the next year?"). Items addressed a range of substances including tobacco, alcohol, inhalants, marijuana, and other illicit drugs. Responses were assessed on a five-point Likert scale ranging from Definitely Not to Definitely Will. Alpha reliability averaged .86 across cohorts and assessment waves. Items were coded so that higher scores represented higher probabilities of future substance use.

Substance Use Expectancies was assessed with eleven items concerning students' expectations of positive outcomes from substance use (e.g., "Drinking alcohol lets you have more fun."). Items addressed expectancies associated with alcohol, tobacco, and marijuana use. Responses were assessed on a five-point Likert scale ranging from Strongly Agree to Strongly Disagree. Alpha reliability averaged .95 across cohorts and assessment waves. Items were coded so that higher scores indicated less positive expectancies.

Attitude Toward Substance Use was assessed with three items (e.g., "How wrong do you think it is for someone your age to smoke cigarettes?"). Items addressed alcohol, tobacco, and marijuana, and other illicit drugs. Responses were assessed on a four-point Likert scale ranging from Not At All Wrong to Very Wrong. Alpha reliability averaged .87 across cohorts and assessment waves. Items were coded so that higher scores represented less favorable attitudes toward substance use.

Perceived Substance Use Norms was assessed with three items addressing peer use of alcohol, tobacco, and marijuana (e.g., "How many people your age do you think drink beer, wine, or liquor?"). Responses were assessed on a four-point Likert scale ranging from None or Almost None to All or Almost All. Alpha reliability averaged .86 across cohorts and assessment waves. Items were coded so that higher scores indicated perceptions of more prevalent substance use.

Problem Solving was assessed with five items addressing problem solving strategies (e.g., "When you have a problem, how often do you think about the consequences of each choice?"). Responses were assessed on a five-point Likert scale ranging from Never to Always. Alpha reliability averaged .93 across cohorts and assessment waves. Items were coded so that higher scores indicated more frequent use of constructive problem solving strategies.

Assertiveness was assessed with five items (e.g., "How likely would you be to express an opinion even though others may disagree with you?"). Responses were assessed on a five- 
point Likert scale ranging from Probably Would Not to Definitely Would. Alpha reliability averaged .76 across cohorts and assessment waves. Items were coded so that higher scores indicated higher likelihoods of assertive behavior.

Association with Antisocial Peers was assessed with three items concerning the degree to which students agreed with statements about their closest friends (e.g., "These friends sometimes break the law"). Responses were assessed on a five-point Likert scale ranging from Strongly Agree to Strongly Disagree. Alpha reliability averaged .82 across cohorts and assessment waves. Items were coded so that higher scores indicated more antisocial behavior on the part of students' closest friends.

\section{Results}

\section{Pretest Equivalence and Differential Attrition}

Initial analyses were conducted to assess pretest equivalence and differential attrition by condition at each follow-up data collection point for key sociodemographic characteristics (child gender, age, grades, absence from school, free and reduced cost school lunch participation, and living with both biological parents) and all youth, parenting, and family functioning outcome measures. Multilevel analyses of variance results showed no significant condition differences at pretest for any sociodemographic or outcome measure. Two instances of statistically significant differential attrition were found, both at the $9^{\text {th }}$ grade follow-up assessment; control group participants who reported lower levels of consistent discipline and lower substance refusal efficacy at pretest dropped out of the project at a higher rate than did similar intervention group students.

\section{Intervention-Control Differences in Family and Youth Outcomes}

Primary outcome analyses were conducted via multilevel (mixed model) analyses of covariance (using SAS PROC MIXED). Analyses were conducted to test for the hypothesized partnership-assisted, community-based intervention effects on child management and family-functioning outcomes. The model included factors associated with the study design (i.e., intervention condition, state, cohort, and block) and controlled for pretest levels of the outcome variables and whether or not the child was living with both biological parents. The multilevel model was necessary to account for the nested design of the study, given that random assignment to experimental condition was at the community/ school district level. Additionally, an intent-to-treat analysis strategy was used to avoid bias associated with self-selection into the family-focused intervention.

Overall, results showed a consistent pattern of modest condition differences favoring the intervention group across outcomes and data collection points. At the $7^{\text {th }}$ grade follow-up, all condition differences were statistically significant for all outcomes except two (affective quality from fathers toward youth and substance refusal efficacy). Seventh grade follow-up results are presented in Table 1. The majority of intervention-control group differences remained significant at the $8^{\text {th }}$ grade follow-up. Results for all parenting outcomes except consistent discipline remained significant, as did all results for parent-child affective quality outcomes significant at the prior wave. In addition, results for the majority of youth attitude and skill outcomes remained significant. However, intervention-control differences for a number of outcomes reflecting attitudes directly relevant to substance use (substance refusal intentions, substance use plans, and attitudes toward substance use) were no longer statistically significant (see Table 2). By the $9^{\text {th }}$ grade follow-up, the number of statistically significant findings decreased substantially, although findings for overall general child management remained significant, as did findings for parent-child activities, and most youth attitude and skill outcomes that were significant at the $8^{\text {th }}$ grade follow-up. Interestingly, 
findings for substance refusal intentions, not significant at the $8^{\text {th }}$ grade follow-up, were significant at the $9^{\text {th }}$ grade assessment (see Table 3 ).

Two types of effect sizes were computed for all outcomes and are reported in Tables 1 to 3 . Effect sizes were computed at both the individual and community levels. Individual-level effect sizes reflect the magnitude of the intervention-control differences in standard deviation units assessed at the individual level (as derived from the multilevel ANCOVA model). Community level effect sizes reflect the magnitude of the intervention-control differences in standard deviation units assessed at the community level. The community level effect sizes are more directly relevant for assessing the community level impact targeted by sustained community-based prevention efforts. In addition, because a relatively small proportion of the study participants in the intervention communities attended the family-focused intervention (approximately 17\%), individual level effect sizes based on intent-to-treat analyses, like those employed here, are likely to underestimate the intervention impact that would be observed if all participants fully participated in the interventions offered. As reported in Table 1, individual level effect sizes for outcomes showing statistically significant intervention-control differences were small, ranging from . 06 (child monitoring) to .12 (family environment). Community level effect sizes were larger, ranging from .37 (child expressions of warmth toward mother) to .65 (family environment) for significant intervention-control differences.

\section{Discussion}

Youth and family protective factor outcomes of evidence-based preventive interventions selected and managed by community teams were examined. Community teams were led by University Extension professionals and supported by a community-university partnership model involving prevention researchers and technical assistance provided via Extensionbased Prevention Coordinators. Results indicated that such community team prevention efforts can be effective in producing a range of positive youth and family outcomes. At the $7^{\text {th }}$ grade assessment, significant intervention effects were found for nearly all parent, youth, and family outcomes examined; most of those effects remained significant at the $8^{\text {th }}$ grade assessment. At the $9^{\text {th }}$ grade assessment, substantially fewer significant effects associated with parenting and the parent-child relationship were found, however, significant findings remained for a variety of youth protective factor outcomes.

Among the 21 outcomes examined, significant intervention effects were not found at any assessment point for only two outcomes, expressions of parent-child affective quality by fathers and youth's substance use refusal efficacy. Weak father's affective quality findings may be due in part to fathers' relatively lower levels of engagement in the family-focused intervention. While nearly all attending families were represented by an adolescent and his or her mother, approximately half of attending families included both parents or an adolescent and a father only. Reasons for the absence of significant findings for substance refusal efficacy are less clear, though it is worth noting that findings for substance refusal intentions, which are expected to be more closely related to actual behaviors, were significant at both the $7^{\text {th }}$ and $9^{\text {th }}$ grade assessments.

The primary importance of the positive intervention effects on the youth, parent, and family outcomes reported here concerns their expected impact on subsequent adolescent problem behaviors, including substance use (e.g., Baumrind, 1991; Brook et al., 1990; Dishion et al., 1991; Hawkins et al., 1992; Loeber \& Dishion, 1983; Maccoby \& Martin, 1983; Mrazek \& Haggerty, 1994; Redmond et al., 1998; Rothbaum \& Weisz, 1994; Spoth et al., 1996; Spoth et al., 1997). This research suggests that significant public health benefits could accrue by widespread implementation of programming to enhance effective parenting, family 
functioning, and protective youth skills and attitudes. Indeed, as previously described, an examination of $7^{\text {th }}$ grade substance use in the current sample shows significant reductions in substance initiation and use among the intervention group relative to controls (Spoth, Redmond, et al., 2007). The current findings, indicating that intervention effects on many protective factor outcomes are sustained through the $9^{\text {th }}$ grade (three and one-half years past baseline), are encouraging in their implications for long-term adolescent problem behavior outcomes. Future research will examine the interrelationships between youth and family protective factor outcomes and the developmental trajectories of adolescent problem behaviors, including substance abuse.

Because the interventions studied here have previously been shown to produce positive effects (e.g., Botvin \& Griffin, 2004; Ellickson et al., 2003; McNeal, Hansen, et al., 2004; Spoth et al., 2005), the most important finding from this study is not that these interventions can produce positive outcomes, but that, when coupled with ongoing technical assistance, they can produce positive outcomes when much of the control over their delivery is turned over to representatives of the communities in which they are implemented. Importantly, results suggest the effectiveness of the technical assistance provided to community teams by the University Extension-based Prevention Coordinators through the PROSPER model. In previous studies, we have found that within this partnership model, community teams were able both to successfully recruit participants and implement evidence-based interventions with fidelity. In the current study, the findings of positive intervention effects indicated that the teams' level of success in supporting both program recruitment and program fidelity were sufficient to affect their targeted population. Moreover, the relatively "real world" conditions under which the interventions were implemented and studied is an important factor in interpreting the results observed; results from these intent-to-treat analyses support the interpretation that community-based prevention programming, delivered by community teams supported by a community-university partnership, can produce community-level effects. However, it should be noted that, while pervasive and statistically significant, intervention effects were generally small in magnitude. Nonetheless, if these protective factor effects translate into expected problem behavior reductions, even relatively small reductions in serious problems (such as alcohol dependence and abuse) can produce substantial economic savings (Spoth, Guyll, Day, 2002).

There are a few limitations to bear in mind when considering the results presented here. Foremost, results are based on evidence-based interventions delivered by community teams in predominantly White, rural and semi-rural towns and small cities. It is unclear if similar Extension-focused community-university partnerships would be as successful in larger or ethnically more diverse cities/urban areas. Although, it should be noted that University Extension operates nationally, and is not limited to primarily rural areas, the role that Extension has in larger urban communities may be quite different than in the communities involved in the current study. Conversely, the finding that PROSPER supported delivery of evidence-based preventive interventions can be effective in rural communities is an important one, as such areas are often underserved with regard to prevention and other health services, having limited capacity to initiate and sustain such services.

In addition, readers should bear in mind that all findings reported here are based on youth reports. Such youth self-reports may be subject to some social desirability biases. However, it seems unlikely that such biases would be substantially different across study conditions, particularly at later waves, two or three years following intervention. Another question concerns the implications of using youth reports of parent behaviors. Youth reports of their parents may be biased (positively or negatively), or be less sensitive to changes in some parent behaviors (e.g., the use of consistent discipline) than parents' own reports would be. 
Demonstrating that partnership-supported community teams can produce a community-level effect on youth, parent, and family protective factors bodes well for the potential public health impact of the PROSPER model, particularly so when considering that effects were assessed versus a comparison condition in which communities were not limited in their own prevention efforts, efforts that sometimes included evidence-based programming. However, ultimately, the long-term public health potential of this dissemination model hinges on both the broader dissemination of well-delivered evidence-based prevention programs and the sustainability of that delivery. Toward that end, the university-community hybrid partnership structure utilized in this study was designed as a potentially sustainable system for the ongoing dissemination of evidence-based programming by community teams. This partnership model was designed to foster local ownership and financial support leading to long-term, high quality implementation of interventions by community teams. Ultimately, external support for intervention implementation is to be only in the form of ongoing technical assistance delivered through a close collaboration between prevention scientists and Extension. Research on the long-term sustainability of the PROSPER model in Iowa and Pennsylvania is underway.

\section{Acknowledgments}

Work on this paper was supported by research grant DA 013709 from the National Institute on Drug Abuse.

\section{References}

Bandura, A. Social learning theory. Englewood Cliffs, NJ: Prentice Hall; 1977.

Bandura, A. Social foundations of thought and action: A social cognitive theory. Englewood Cliffs, NJ: Prentice-Hall; 1986.

Baumrind D. The influence of parenting style on adolescent competence and substance use. Journal of Early Adolescence. 1991; 11:56-95.

Biglan, A.; Brennan, PA.; Foster, SL.; Holder, HD.; Miller, TL.; Cunningham, PB., et al. Helping adolescents at risk: Prevention of multiple problem behaviors. New York: Guilford; 2004.

Botvin, GJ. Life Skills Training and the prevention of adolescent drug abuse. In: Clark, D., editor. Preparing youth for the 21st century. Washington, DC: The Aspen Institute; 1996.

Botvin, GJ. Life Skills Training. Princeton, NJ: Princeton Health Press; 2000.

Botvin GJ, Griffin KW. Life Skills Training: Empirical findings and future directions. Journal of Primary Prevention. 2004; 25:211-232.

Brook JS, Brook DW, Gordon AS, Whiteman M, Cohen P. The psychosocial etiology of adolescent drug use: A family interactional approach. Genetic, Social, and General Monographs. 1990; 116:111-267.

Butterfoss FD, Goodman RM, Wandersman A. Community coalitions for prevention and health promotion: Factors predicting satisfaction, participation, and planning. Health Education Quarterly. 1996; 23:65-79. [PubMed: 8822402]

DeMarsh, JP.; Kumpfer, KL. Family-oriented interventions for the prevention of chemical dependency in children and adolescents. In: Griswold-Ezekoye, S.; Kumpfer, KL.; Bukowski, WJ., editors. Childhood and chemical abuse: Prevention and intervention. New York, NY: Haworth Press; 1986. p. 117-151.

Dishion, TJ.; Andrews, DW.; Kavanagh, K.; Soberman, LH. Preventive Interventions for High-Risk Youth: The Adolescent Transitions Program. In: Peters, RD.; McMahon, RJ., editors. Preventing Childhood Disorders, Substance Abuse, and Delinquency. Thousand Oaks, Calif: Sage; 1996. p. 184-214.

Dishion TJ, Patterson GR, Stoolmiller M, Skinner ML. Family, school, and behavioral antecedents to early adolescent involvement with antisocial peers. Developmental Psychology. 1991; 27(1):172180. 
Dzewaltowski DA, Estabrooks PA, Klesges LM, Sheana Bull S, Glasgow RE. Behavior change intervention research in community settings: how generalizable are the results? Health Promotion International. 2004; 19(2):235-245. [PubMed: 15128715]

Ellickson PL, McCaffery DF, Ghosh-Dastidar B, Longshore DL. New inroads in preventing adolescent drug use: Results from a large-scale trial of Project ALERT. American Journal of Public Health. 2003; 93:1830-1836. [PubMed: 14600049]

Flay BR, Biglan A, Boruch RF, Castro FG, Gottfredson D, Kellam S, et al. Standards of evidence: Criteria for efficacy, effectiveness and dissemination. Prevention Science Online. 200510.1007/ s11121-005-5553-y

Glasgow RE, Klesges LM, Dzewaltowski DA, Bull SS, Estabrooks P. The future of health behavior change research: What is needed to improve translation of research into health promotion practice? Annals of Behavioral Medicine. 2004; 27:3-12. [PubMed: 14979858]

Haggerty, K.; Kosterman, R.; Catalano, RF.; Hawkins, JD. OJJDP Juvenile Justice Bulletin (NCJ 173408). Washington, DC: U.S. Department of Justice, Office of Juvenile Justice and Delinquency Prevention; 1999. Preparing for the Drug Free Years.

Hawkins JD, Catalano RF, Miller JY. Risk and protective factors for alcohol and other drug problems in adolescence and early adulthood: Implications for substance abuse prevention. Psychological Bulletin. 1992; 112:64-105. [PubMed: 1529040]

Hansen, WB. Prevention programs: What are the critical factors that spell success?. Plenary Session presented at the NIDA National Conference on Drug Abuse Prevention Research; Washington, DC. 1996.

Jessor, R.; Jessor, SL. Problem behavior and psychosocial development: A longitudinal study of youth. New York: Academic Press; 1977.

Johnston, LD.; Bachman, PM.; O’Malley, JG.; Schulenberg, JE. Monitoring the Future national results on adolescent drug use: Overview of key findings, 2005 (NIH publication number 06-5882). Bethesda Maryland: National Institute on Drug Abuse; 2006.

Kumpfer, KL.; Molgaard, V.; Spoth, R. The Strengthening Families Program for the prevention of delinquency and drug use. In: Peters, RD.; McMahon, RJ., editors. Preventing childhood disorders, substance abuse, and delinquency. Thousand Oaks, CA: Sage; 1996. p. 241-267.

Kumpfer KL, Turner C, Hopkins R, Librett J. Leadership and team effectiveness in community coalitions for the prevention of alcohol and other drug abuse. Health Education Research. 1993; 8:359-374.

Loeber R, Dishion T. Early predictors of male delinquency: A review. Psychological Bulletin. 1983; 93:68-99. [PubMed: 6353467]

Maccoby, EE.; Martin, JA. Socialization in the context of the family: Parent-child interaction. In: Mussen, PH., editor. Handbook of child psychology, 4th ed. Vol. 4. New York: Wiley; 1983. p. $1-101$.

McNeal RB, Hansen WB, Harrington NG, Giles SM. How All Stars works: An examination of program effects on mediating variables. Health Education \& Behavior. 2004; 31:165-178. [PubMed: 15090119]

Mihalic SF, Irwin K. Blueprints for violence prevention: From research to real- world settingsfactors influencing the successful replication of model programs. Youth Violence and Juvenile Justice. 2003; 1:307-329.

Minkler, M.; Wallerstein, N., editors. Community-based participatory research for health. San Francisco, CA: Jossey-Bass; 2002.

Molgaard, VM.; Kumpfer, KL.; Fleming, E. Strengthening Families Program for Parents and Youth 10-14: A video-based curriculum. Ames, IA: Institute for Social and Behavioral Research; 1997.

Molgaard, VM.; Spoth, RL. Strengthening Families Program for young adolescents: Overview and outcomes. In: Pfeiffer, SI.; Reddy, LA., editors. Innovative mental health programs for children: Programs that work. Binghamton, NY: Haworth Press; 2001. p. 15-29.

Molgaard, VM.; Spoth, RL.; Redmond, C. OJJDP Juvenile Justice Bulletin (NCJ 182208). Washington, DC: U.S. Department of Justice, Office of Juvenile Justice and Delinquency Prevention; 2000. Competency training: The Strengthening Families Program for Parents and Youth 10-14. 
Moos, RH.; Moos, BS. Family Environment Scale Manual. Palo Alto, CA: Consulting Psychologists Press; 1986.

Mrazek, P.; Haggerty, R., editors. Reducing risks for mental disorders: Frontiers for preventive intervention research. Washington, DC: National Academy Press; 1994.

Redmond, C.; Spoth, RL.; Shin, C. Adolescent propensity to use alcohol: Long-term outcomes of a universal family-focused preventive intervention. Symposium paper presented at the Society for Prevention Research Sixth Annual Meeting; Park City, UT. 1998 Jun.

Romer, D., editor. Reducing adolescent risk: Toward an integrated approach. Thousand Oaks, CA: Sage; 2003.

Rosenstock IM, Strecher VJ, Becker MH. Social learning theory and the Health Belief Model. Health Education Quarterly. 1988; 15:175-183. [PubMed: 3378902]

Rothbaum F, Weisz JR. Parental caregiving and child externalizing behavior in nonclinical samples: A meta-analysis. Psychological Bulletin. 1994; 116:55-74. [PubMed: 8078975]

Spanier CA. The prevention of depression: Protective mechanisms of maintenance interpersonal psychotherapy. Dissertation Abstracts International. 1998; 58(10-B)

Spoth RL, Clair S, Greenberg MT, Redmond C, Shin C. Toward dissemination of evidence-based family interventions: Maintenance of community-based partnership recruitment results and associated factors. Journal of Family Psychology. 2007; 21:137-145. [PubMed: 17605536]

Spoth RL, Greenberg MT. Toward a comprehensive strategy for effective practitioner-scientist partnerships and larger-scale community benefits. American Journal of Community Psychology. 2005; 35:107-126. [PubMed: 15909789]

Spoth RL, Greenberg MT, Bierman K, Redmond C. PROSPER Community-university partnership model for public education systems: Capacity-building for evidence-based, competence-building prevention. Prevention Science. 2004; 5:31-39. [PubMed: 15058910]

Spoth R, Guyll M, Day SX. Universal family-focused interventions in alcohol-use disorder prevention: Cost-effectiveness and cost-benefit analyses of two interventions. Journal of Studies on Alcohol. 2002; 63:219-228. [PubMed: 12033699]

Spoth RL, Guyll M, Lillehoj CJ, Redmond C, Greenberg MT. PROSPER study of evidence-based intervention implementation quality by community-university partnerships. Journal of Community Psychology. 2007; 35:981-999. [PubMed: 20376336]

Spoth RL, Randall GK, Shin C, Redmond C. Randomized study of combined universal family and school preventive interventions: Patterns of long-term effects on initiation, regular use, and weekly drunkenness. Psychology of Addictive Behaviors. 2005; 19:372-381. [PubMed: 16366809]

Spoth RL, Redmond C, Shin C, Greenberg MT, Clair S, Feinberg M. Substance use outcomes at 18 months past baseline from the PROSPER community- university partnership trial. American Journal of Preventive Medicine. 2007; 32:395-402. [PubMed: 17478265]

Spoth RL, Redmond C, Hockaday C, Yoo S. Protective factors and young adolescent tendency to abstain from alcohol use: A model using two waves of intervention study data. American Journal of Community Psychology. 1996; 24:749-770. [PubMed: 9194328]

Spoth RL, Redmond C, Shin C. Randomized trial of brief family interventions for general populations: Adolescent substance use outcomes four years following baseline. Journal of Consulting and Clinical Psychology. 2001; 69:627-642. [PubMed: 11550729] 
Table 1

Protective Factor Outcomes at $1 \frac{1 / 2}{2}$ Years Past Baseline ( $7^{\text {th }}$ Grade)

\begin{tabular}{|c|c|c|c|c|}
\hline Outcome variable & $\begin{array}{c}\text { Intervention LS Mean } \\
(S E)\end{array}$ & $\begin{array}{l}\text { Control LS Mean } \\
\qquad(S E)\end{array}$ & $F$-value $(1,12)$ & Effect Size $^{a}$ (Ind./Comm.) \\
\hline General child management (overall) & $3.91(.014)$ & $3.86(.014)$ & $12.39^{* *}$ & $.09 / .63$ \\
\hline Consistent discipline & $3.69(.022)$ & $3.63(.022)$ & $4.57^{*}$ & $.06 / .52$ \\
\hline Harsh discipline & $3.57(.025)$ & $3.49(.025)$ & $6.51^{*}$ & $.06 / .46$ \\
\hline Child monitoring & $4.38(.014)$ & $4.34(.014)$ & $4.39 *$ & $.06 / .55$ \\
\hline Inductive reasoning & $3.55(.026)$ & $3.48(.026)$ & $3.98^{*}$ & $.06 / .35$ \\
\hline Parent-child affective quality (overall) & $4.01(.020)$ & $3.95(.020)$ & $3.70^{*}$ & $.06 / .22$ \\
\hline From mother & $4.19(.021)$ & $4.14(.021)$ & $3.71^{*}$ & $.06 / .36$ \\
\hline From father & $3.96(.022)$ & $3.91(.022)$ & 3.05 & $.05 / .11$ \\
\hline Toward mother & $4.03(.020)$ & $3.97(.020)$ & $5.27^{*}$ & $.07 / .36$ \\
\hline Toward father & $3.91(.022)$ & $3.83(.022)$ & $6.75^{*}$ & $.08 / .30$ \\
\hline Parent-child activities & $3.89(.024)$ & $3.76(.024)$ & $13.67^{* *}$ & $.11 / .43$ \\
\hline Family environment & $3.58(.018)$ & $3.49(.018)$ & $20.11^{* *}$ & $.13 / .69$ \\
\hline Substance refusal intentions & $4.68(.017)$ & $4.64(.017)$ & $5.13 *$ & $.07 / .66$ \\
\hline Substance refusal efficacy & $4.41(.027)$ & $4.37(.027)$ & 0.96 & $.04 / .42$ \\
\hline Substance use plans & $1.21(.012)$ & $1.25(.012)$ & $4.05^{*}$ & $.07 / .54$ \\
\hline Substance use expectancies & $4.66(.019)$ & $4.57(.019)$ & $20.86^{* *}$ & $.14 / .86$ \\
\hline Attitude toward substance use & $3.58(.017)$ & $3.52(.017)$ & $10.69^{* *}$ & $.10 / .75$ \\
\hline Perceived substance use norms & $2.22(.045)$ & $2.34(.045)$ & $4.09^{*}$ & $.14 / .55$ \\
\hline Problem solving & $3.62(.025)$ & $3.46(.024)$ & $24.27^{* *}$ & $.15 / .71$ \\
\hline Assertiveness & $4.22(.015)$ & $4.16(.015)$ & $10.32^{* *}$ & $.10 / .61$ \\
\hline Association with antisocial peers & $1.67(.020)$ & $1.78(.020)$ & $14.76^{* *}$ & $.13 / .81$ \\
\hline
\end{tabular}

Note.

$p<0.05$

*** $p$ < 0.01 (one-tailed tests). Multilevel ANCOVA model incorporating condition, state, cohort, and block as factors, and controlling for pretest levels of outcomes and living with both biological parents.

${ }^{a}$ Effect sizes computed at the individual (based on the multilevel model) and community levels. 
Table 2

Protective Factor Outcomes at $2 \frac{1 / 2}{2}$ Years Past Baseline ( $8^{\text {th }}$ Grade)

\begin{tabular}{|c|c|c|c|c|}
\hline Outcome variable & $\begin{array}{c}\text { Intervention LS Mean } \\
(S E)\end{array}$ & $\begin{array}{c}\text { Control LS Mean } \\
(S E)\end{array}$ & $F$-value $(1,12)$ & Effect Size $^{a}$ (Ind./Comm.) \\
\hline General child management (overall) & $3.82(.015)$ & $3.77(.015)$ & $7.01^{*}$ & $.08 / .66$ \\
\hline Consistent discipline & $3.65(.025)$ & $3.62(.025)$ & 0.56 & $.03 / .19$ \\
\hline Harsh discipline & $3.50(.027)$ & $3.42(.027)$ & $6.73^{*}$ & $.07 / .68$ \\
\hline Child monitoring & $4.27(.016)$ & $4.22(.016)$ & $5.74^{*}$ & $.06 / .73$ \\
\hline Inductive reasoning & $3.39(.023)$ & $3.22(.023)$ & $4.97^{*}$ & $.06 / .50$ \\
\hline Parent-child affective quality (overall) & $3.82(.021)$ & $3.73(.021)$ & $12.11^{* *}$ & $.09 / .53$ \\
\hline From mother & $4.07(.025)$ & $3.98(.025)$ & $15.24^{* *}$ & $.09 / .58$ \\
\hline From father & $3.74(.026)$ & $3.71(.026)$ & 0.76 & $.03 / .26$ \\
\hline Toward mother & $3.82(.024)$ & $3.72(.024)$ & $9.88^{* *}$ & $.09 / .60$ \\
\hline Toward father & $3.64(.025)$ & $3.58(.025)$ & $3.38^{*}$ & $.05 / .39$ \\
\hline Parent-child activities & $3.65(.026)$ & $3.52(.026)$ & $11.40^{* *}$ & $.10 / .55$ \\
\hline Family environment & $3.47(.016)$ & $3.40(.016)$ & $14.36^{* *}$ & $.11 / .62$ \\
\hline Substance refusal intentions & $4.52(.025)$ & $4.50(.025)$ & 0.41 & $.03 / .45$ \\
\hline Substance refusal efficacy & $4.31(.031)$ & $4.31(.032)$ & 0.01 & $.00 / .23$ \\
\hline Substance use plans & $1.36(.019)$ & $1.37(.019)$ & 0.12 & $.02 / .27$ \\
\hline Substance use expectancies & $4.53(.023)$ & $4.46(.023)$ & $7.09^{*}$ & $.10 / .68$ \\
\hline Attitude toward substance use & $3.40(.023)$ & $3.36(.023)$ & 1.44 & $.05 / .49$ \\
\hline Perceived substance use norms & $2.47(.054)$ & $2.61(.054)$ & $4.80^{*}$ & $.16 / .64$ \\
\hline Problem solving & $3.59(.029)$ & $3.45(.029)$ & $14.67^{* *}$ & $.13 / .63$ \\
\hline Assertiveness & $4.24(.015)$ & $4.21(.015)$ & $3.40^{*}$ & $.05 / .39$ \\
\hline Association with antisocial peers & $1.87(.028)$ & $1.97(.028)$ & $6.96^{*}$ & $.11 / .75$ \\
\hline
\end{tabular}

Note.

* $p<0.05$;

$p<0.01$ (one-tailed tests). Multilevel ANCOVA model incorporating condition, state, cohort, and block as factors, and controlling for pretest levels of outcomes and living with both biological parents.

${ }^{a}$ Effect sizes computed at the individual (based on the multilevel model) and community levels. 
Table 3

Protective Factor Outcomes at $3 \frac{1}{2} 2$ Years Past Baseline ( $9^{\text {th }}$ Grade)

\begin{tabular}{|c|c|c|c|c|}
\hline Outcome variable & $\begin{array}{c}\text { Intervention LS Mean } \\
(S E)\end{array}$ & $\begin{array}{c}\text { Control LS Mean } \\
(S E)\end{array}$ & $F$-value $(1,12)$ & Effect Size $^{a}$ (Ind./Comm.) \\
\hline General child management (overall) & $3.71(.015)$ & $3.67(.015)$ & $4.47^{*}$ & $.06 / .50$ \\
\hline Consistent discipline & $3.61(.020)$ & $3.58(.020)$ & 1.06 & $.03 / .15$ \\
\hline Harsh discipline & $3.44(.024)$ & $3.42(.024)$ & 0.35 & $.02 / .23$ \\
\hline Child monitoring & $4.12(.022)$ & $4.07(.021)$ & 3.06 & $.07 / .61$ \\
\hline Inductive reasoning & $3.24(.023)$ & $3.21(.023)$ & 0.84 & $.02 / .23$ \\
\hline Parent-child affective quality (overall) & $3.67(.017)$ & $3.63(.017)$ & 2.95 & $.04 / .09$ \\
\hline From mother & $3.93(.022)$ & $3.92(.022)$ & 0.17 & $.01 / .05$ \\
\hline From father & $3.59(.025)$ & $3.58(.025)$ & 0.31 & $.02 / .05$ \\
\hline Toward mother & $3.67(.021)$ & $3.64(.021)$ & 0.78 & $.02 / .05$ \\
\hline Toward father & $3.47(.023)$ & $3.45(.023)$ & 0.79 & $.02 / .09$ \\
\hline Parent-child activities & $3.39(.022)$ & $3.32(.022)$ & $4.04^{*}$ & $.05 / .10$ \\
\hline Family environment & $3.36(.018)$ & $3.33(.018)$ & 1.80 & $.05 / .25$ \\
\hline Substance refusal intentions & $4.39(.029)$ & $4.32(.029)$ & $3.32^{*}$ & $.09 / .74$ \\
\hline Substance refusal efficacy & $4.24(.034)$ & $4.17(.034)$ & 2.12 & $.07 / .62$ \\
\hline Substance use plans & $1.50(.027)$ & $1.54(.027)$ & 0.79 & $.05 / .47$ \\
\hline Substance use expectancies & $4.35(.034)$ & $4.24(.034)$ & $5.39^{*}$ & $.14 / .91$ \\
\hline Attitude toward substance use & $3.19(.033)$ & $3.12(.032)$ & 2.30 & $.08 / .68$ \\
\hline Perceived substance use norms & $2.90(.055)$ & $3.10(.055)$ & $6.63^{*}$ & $.24 / .84$ \\
\hline Problem solving & $3.56(.029)$ & $3.45(.029)$ & $8.47^{* *}$ & $.10 / .48$ \\
\hline Assertiveness & $4.25(.018)$ & $4.20(.018)$ & $3.40^{*}$ & $.07 / .33$ \\
\hline Association with antisocial peers & $1.99(.035)$ & $2.11(.035)$ & $5.10^{*}$ & $.12 / .84$ \\
\hline
\end{tabular}

Note.

${ }^{*}<0.05$;

**

$p<0.01$ (one-tailed tests). Multilevel ANCOVA model incorporating condition, state, cohort, and block as factors, and controlling for pretest levels of outcomes and living with both biological parents.

${ }^{a}$ Effect sizes computed at the individual (based on the multilevel model) and community levels. 